Revista Brasil. Bot., V.32, n.1, p.1-10, jan.-mar. 2009

\title{
Composição florística e estrutura da vegetação arbustivo-arbórea em um cerrado rupestre, Cocalzinho de Goiás, Goiás
}

\author{
JOSÉ ROBERTO RODRIGUES PINTO ${ }^{1,4}$, EDDIE LENZA² e \\ ALEXANDRE DE SIQUEIRA PINTO ${ }^{3}$
}

(recebido: 02 de março de 2006; aceito: 23 de outubro de 2008)

\begin{abstract}
Floristic composition and structure of woody vegetation in a cerrado rupestre, Cocalzinho de Goiás, Goiás State, Brazil). A vegetation survey of the woody species (at least $5 \mathrm{~cm}$ of trunk diameter at $30 \mathrm{~cm}$ above the ground) was conducted in

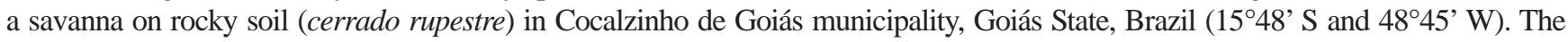
objective was to compare the structure characteristics and the floristics of cerrado rupestre with those features found in cerrado stricto sensu areas occuring on deep soils in Central Brazil. The sample consisted in 1.0 hectare (ten plots, $20 \times 50 \mathrm{~m}$ ) in cerrado rupestre. The cerrado rupestre studied showed structural similarities with the physiognomy of open cerrado (cerrado ralo). The richness and the species diversity are similar with other Brazilian savanna (cerrado stricto sensu areas of Brazil Central). The floristic composition revealed species predominantly from other physiognomies from the cerrado stricto sensu and to a lesser extent, species from forest formations from the bioma and endemics from this rocky environment. The floristic richness and diversity is similar to other savanna areas of Central Brazil. In structural terms, the density and basal area are similar to values found in open cerrado vegetation. The limiting environmental conditions, mainly edaphics, do not result in expressive changes in floristic composition, richness, and species diversity, but promoted reduction in density and basal area of the wood species in the cerrado rupestre studied.
\end{abstract}

Key words - Central Brazil, Cerrado, phytosociology, rocky soil environment

RESUMO - (Composição florística e estrutura da vegetação arbustivo-arbórea em um cerrado rupestre, Cocalzinho de Goiás, Goiás). Foi realizado um levantamento da vegetação arbutivo-arbórea (indivíduos com diâmetro a $30 \mathrm{~cm}$ do solo $\geq 5 \mathrm{~cm}$ ), em 1,0 hectare de cerrado rupestre (dez parcelas de $20 \times 50 \mathrm{~m}$ ), localizado em Cocalzinho de Goiás, Goiás, Brasil $\left(15^{\circ} 48^{\prime} \mathrm{S}\right.$ e $48^{\circ} 45^{\prime} \mathrm{W}$ ). O objetivo foi avaliar e comparar as relações florísticas e as características estruturais deste cerrado sobre afloramentos rochosos com aquelas encontradas nos estudos já realizados em áreas de cerrado sentido restrito sobre solos profundos, localizados no Brasil Central. A composição florística do cerrado rupestre estudado é formada predominantemente por espécies das fitofisionomias do cerrado sentido restrito e em menor contribuição por espécies das formações florestais do bioma e espécies endêmicas de ambientes rupestres. A riqueza e a diversidade de espécies estão dentro dos limites normalmente encontrados para as áreas de cerrado sentido restrito do Brasil Central. Em termos estruturais, a densidade e área basal se assemelham aos valores registrados na subdivisão fitofisionômica de cerrado ralo. As condições ambientais limitantes, principalmente edáficas, não resultaram em mudanças expressivas na composição florística, riqueza e diversidade de espécies, mas refletiram em redução da densidade e área basal da vegetação arbustivo-arbórea do cerrado rupestre estudado.

Palavras-chave - ambiente rupestre, Brasil Central, Cerrado, fitossociologia

\section{Introdução}

Estudos envolvendo o bioma Cerrado existem desde meados do século XIX (Warming 1973), a maioria realizados em áreas com relevo plano a levemente ondulado e localizados nos planaltos sobre solos profundos (Felfili et al. 2001, Ratter et al. 2003). Por outro lado, estudos em áreas de cerrado situadas em

1. Universidade de Brasília, Departamento de Engenharia Florestal, Caixa Postal 04357, 70919-970 Brasília, DF, Brasil.

2. Universidade do Estado de Mato Grosso, Nova Xavantina, Caixa Postal 08, 78690-000 Nova Xavantina, MT, Brasil.

3. Faculdades Integradas da Terra de Brasília, Ciências Biológicas, Quadra 203 - Área Especial Lote 32, 72610-300 Recanto das Emas, DF, Brasil.

4. Autor para correspondência: jrrpinto@unb.br ambientes rupestres, ou seja, em altitudes elevadas e sobre afloramentos rochosos, ainda são incipientes. Segundo Reatto et al. (1998), as áreas sobre solos litólicos e afloramentos rochosos ocupam cerca de 7,3\%, dos mais de 2,0 milhões de $\mathrm{km}^{2}$ ocupados pelo bioma.

Existe uma grande controvérsia no uso do termo rupestre nas áreas onde a vegetação ocorre sobre solos rochosos em altitudes elevadas (Oliveira-Filho \& Fluminhan-Filho 1999, Walter 2006). Tal controvérsia ocorre devido à variação fisionômica apresentada pela vegetação dos altos das montanhas e serras, além da sua complexa e gradual transição para as fisionomias adjacentes Oliveira-Filho \& Fluminhan-Filho (1999). No bioma Cerrado, entretanto, a distinção entre as subdivisões fitofisionômicas situadas em ambientes rupestres é de certa forma simples. Segundo o sistema de classificação 
da vegetação proposto por Ribeiro \& Walter (1998), elas são classificadas em campo rupestre e cerrado rupestre. Estas duas fitofisionomias geralmente estão situadas em altitudes elevadas e sobre afloramentos rochosos, porém o campo rupestre faz parte das formações campestres do bioma, apresentando menos de 5\% de cobertura arbórea, enquanto o cerrado rupestre pertence às formações savânicas, cuja cobertura arbórea varia de 5\% a $70 \%$. Além disso, cada um desses subtipos vegetacionais apresenta composição florística distinta, possuindo flora típica e com particular endemismo (Harley 1995).

Com isto, vários estudos realizados no bioma Cerrado retratam a vegetação localizada em ambientes rupestres de forma generalizada, levando em consideração apenas o fato de estarem sobre afloramentos rochosos e em altitudes elevadas. Muitas vezes a vegetação ali existente é denominada campo rupestre, quando na verdade seria melhor caracterizada como cerrado rupestre, de acordo com o sistema de Ribeiro \& Walter (1998). Para Walter (2006) tais generalizações resultam em interpretações equivocadas quando são analisadas as formas de vida por fitofisionomias, por exemplo, a maior riqueza de espécies arbóreas em campo rupestre sensu lato do que em cerrado sensu stricto. Existem ainda estudos onde a vegetação é descrita apenas como sendo cerrado no sentido restrito sem especificar o subtipo fitofisionômico, ou seja, se é cerrado denso, cerrado típico, cerrado ralo ou cerrado rupestre, dificultando a identificação do subtipo estudado, principalmente, o mais distinto deles que é o cerrado rupestre.

Estudos em ambientes rupestres no bioma Cerrado se restringem aos campos rupestres e, particularmente, à ecologia de populações endêmicas da flora herbáceosubarbustiva (Pirani et al. 1994, Harley 1995, OliveiraFilho \& Fluminhan-Filho 1999, Romero \& Nakajima 1999, Simon \& Proença 2000). O cerrado rupestre é, portanto, um dos subtipos fitofisionômicos do Cerrado menos estudado e, de acordo com Oliveira-Filho \& FluminhanFilho (1999), é merecedor de alta prioridade de conservação e de investigações científicas, pois é comum encontrar espécies endêmicas ou de ocorrência restrita nesses ambientes, além de apresentar alta riqueza florística.

Segundo Meira Neto \& Saporetti Júnior (2002), muitas áreas na região de domínio do Cerrado ainda não foram florística e estruturalmente estudadas. Neste caso, a análise estrutural da vegetação, por meio de levantamentos fitossociológicos, coloca-se como uma das alternativas para se conhecer as variações florísticas, fisionômicas e estruturais a que as comunidades vegetais estão sujeitas (Scolforo 1993). De acordo com Martins (2004), os estudos fitossociológicos consistem na investigação das causas e efeitos da co-habitação de plantas em um dado ambiente e abrange desde a descrição de uma comunidade vegetal local até investigações de padrões recorrentes da vegetação numa escala geográfica. Além disso, esses estudos permitem comparações entre áreas distintas com a mesma fitofisionomia, ou distintas fitofisionomias numa mesma área (Martins 1991).

O presente estudo tem como objetivo avaliar e comparar as relações florísticas e a estrutura fitossociológica do componente arbustivo-arbóreo de um cerrado rupestre, localizado no Município de Cocalzinho de Goiás, GO com aquelas de outros subtipos fitofisionômicos de cerrado sentido restrito do Brasil Central.

\section{Material e métodos}

Local de estudo - O estudo foi realizado em uma área de cerrado rupestre (sensu Ribeiro \& Walter 1998) localizada na Fazenda Cabana dos Pireneus, distante cerca de 1,0 km de Cocalzinho de Goiás, GO. A área está situada nas encostas da Serra dos Pireneus, com altitude média de $1.200 \mathrm{~m}$, posicionada a oeste de Brasília na coordenada geográfica $15^{\circ} 48^{\prime} \mathrm{S}$ e $48^{\circ} 45^{\prime} \mathrm{W}$, próximo ao Parque Estadual dos Pireneus, GO.

A temperatura média anual da região varia entre 20 e $22{ }^{\circ} \mathrm{C}$, podendo ser inferior a $20^{\circ} \mathrm{C}$ em altitudes superiores a $1.200 \mathrm{~m}$ (Nimer 1989), como é o caso da área de cerrado rupestre estudada. A precipitação média anual varia de 1.500 a $1.750 \mathrm{~mm}$, com um período chuvoso e quente entre os meses de outubro a abril e outro seco e frio de maio a setembro (Nimer 1989).

O relevo é bastante movimentado com constantes afloramentos rochosos (arenito e quartzito). Nos afloramentos, onde existe solo, este é normalmente raso, arenoso e formado por uma estreita camada organo-arenosa depositada diretamente sobre a rocha matriz. Quando o relevo é do tipo plano a levemente inclinado pode ocorrer acúmulo de solo arenoso originário da decomposição da rocha matriz (Ribeiro $\&$ Walter 1998), às vezes podendo ocorrer manchas de solos húmicos e até mesmo orgânicos.

Em geral, os solos na área de estudo são Neossolos Quartzarênicos e com afloramentos rochosos derivados de Quartzito. Onde a condição ambiental é mais úmida há acúmulo de húmus que torna o solo mais escuro, semelhante aos solos descritos por Eiten (1994), em áreas de cerrado sobre afloramentos rochosos em outras regiões. Normalmente, este tipo de substrato está sujeito a fortes enxurradas e períodos de alagamento durante a estação chuvosa, bem como forte déficit hídrico na estação seca (Reatto et al. 1998, Oliveira-Filho \& Fluminhan-Filho 1999, Oliveira-Filho \& Ratter 2002, Benites et al. 2003).

A vegetação nativa da região é caracterizada como tipicamente de Cerrado, com suas várias formações fitofisionômicas. Devido à grande variação pedológica, ocorrem diferentes tipos de solos em curtas distâncias. Nas áreas de baixadas onde há deposição de matéria orgânica e material intemperizado das rochas quartzíticas ocorrem 
campo limpo e campo sujo. Nas áreas mais íngremes e com afloramentos rochosos se desenvolvem os campos rupestres e os cerrados rupestres. Na parte alta do relevo e onde a camada de solo é mais espessa e fértil ocorrem as florestas estacionais semideciduais. As matas de galeria e veredas estão associadas aos cursos d'água no fundo dos vales, margeando os canais de drenagens e áreas de nascentes, respectivamente.

Levantamento dos dados - Foram demarcadas aleatoriamente, nas áreas de cerrado rupestre sobre afloramentos rochosos, 10 parcelas de $20 \times 50 \mathrm{~m}$, totalizando 1,0 ha de área amostrada. A maior extensão da parcela ficou paralela ao gradiente topográfico, conforme sugere Oliveira-Filho (1994). O perímetro de cada parcela foi determinado com auxílio de trena, sendo a declividade do terreno corrigida por meio do nivelamento da trena.

Para realização do levantamento da vegetação foram amostrados todos os indivíduos arbustivo-arbóreos vivos contidos no interior das parcelas e que possuíssem diâmetro a $30 \mathrm{~cm}$ do solo - DAS $\geq 5 \mathrm{~cm}$. Para cada indivíduo amostrado foram anotadas informações quanto à identificação botânica, o DAS e a altura total. A altura total foi mensurada com auxílio de régua telescópica de 7,0 $\mathrm{m}$ de comprimento, graduada em centímetros. Nos casos de indivíduos que apresentaram ramificações abaixo de $30 \mathrm{~cm}$ foi calculada a média quadrática das ramificações.

O material botânico amostrado foi herborizado e posteriormente feita a identificação taxonômica através de consultas à literatura específica, ao acervo do Herbário da
Universidade de Brasília (UB) e a especialistas. O sistema de classificação botânica utilizado foi o de "Angiosperm Phylogeny Group" (APG II 2003) e a nomenclatura botânica foi conferida com o banco de dados eletrônico disponibilizado pelo Missouri Botanical Garden (www.mobot.org). A coleção botânica testemunha foi depositada no Herbário UB.

Análise dos dados - A estrutura da vegetação foi descrita com base nas distribuições de frequiências nas classes de diâmetro e de altura e nos parâmetros fitossociológicos (Mueller-Dombois \& Ellenberg 1974). Os parâmetros fitossociológicos e os índices de diversidade de Shannon e de eqüabilidade de Pielou foram calculados com o auxílio do programa FITOPAC (Shepherd 1994). As comparações foram realizadas com base na riqueza de espécies, índices de similaridade florística de Sørensen (Kent \& Coker 1992) e de diversidade de Shannon (Mueller-Dombois \& Ellenberg 1974), bem como na densidade e na área basal entre a área do presente estudo e de outras áreas de cerrado rupestre e cerrado sentido restrito sobre solos profundos do Brasil Central.

\section{Resultados}

Foram registrados 674 indivíduos, pertencentes a 65 espécies, distribuídas em 49 gêneros e 36 famílias botânicas (tabela 1), o que resultou em índice de diversidade de Shannon de 3,45 nats indivíduos ${ }^{-1}$, índice de eqüabilidade de Pielou de 0,827 e área basal total de $5,6720 \mathrm{~m}^{2}$.

Tabela 1. Famílias e espécies arbustivo-arbóreas (DAS $\geq 5 \mathrm{~cm}$ ), registradas no interior das 10 parcelas de $20 \times 50 \mathrm{~m}$ amostradas em um cerrado rupestre, Cocalzinho de Goiás, Goiás. As espécies estão dispostas em ordem decrescente de valor de importância. Onde: $(\mathrm{Nr}=$ número de registro no Herbário da Universidade de Brasília, $\mathrm{N}=$ número de indivíduos, $\mathrm{P}=$ número de parcelas com ocorrência, $\mathrm{AB}=$ área basal $\left(\mathrm{m}^{2}\right)$ e $\mathrm{VI}=$ valor de importância).

Table 1. Families and species of trees and shrubs (diameter individuals at $30 \mathrm{~cm}$ above the ground level $\geq 5 \mathrm{~cm}$ ), sampled on ten $20 \times 50 \mathrm{~m}$ plots in a cerrado rupestre, Cocalzinho de Goiás, Goiás State, Brazil. Species are arranged in decresing order with respect their importance value. ( $\mathrm{Nr}=$ registration number at the UB Herbarium, $\mathrm{N}=$ number of individuals, $\mathrm{P}=$ number of plots where the species is present, $\mathrm{AB}=$ basal area $\left(\mathrm{m}^{2}\right)$ and $\mathrm{VI}=$ importance value $)$.

\begin{tabular}{lllrrrr}
\hline Espécie & Família & $\mathrm{Nr}$ & $\mathrm{N}$ & $\mathrm{P}$ & $\mathrm{AB}$ & $\mathrm{VI}$ \\
\hline Psidium myrsinoides O. Berg & Myrtaceae & 318 & 94 & 10 & 0,4530 & 26,08 \\
Miconia burchellii Triana & Melastomataceae & 310 & 47 & 9 & 0,4936 & 19,41 \\
Anacardium occidentale L. & Anacardiaceae & & 50 & 10 & 0,3345 & 17,47 \\
Plenckia populnea Reissek & Celastraceae & & 42 & 9 & 0,2850 & 14,99 \\
Sclerolobium paniculatum Vogel & Fabaceae & & 20 & 7 & 0,5041 & 14,76 \\
Qualea parviflora Mart. & Vochysiaceae & 336 & 29 & 8 & 0,3880 & 14,46 \\
Schwartzia adamantium (Cambess.) Gir.-Cañas & Marcgraviaceae & & 12 & 9 & 0,4223 & 12,96 \\
Hymenaea stigonocarpa Mart. ex Hayne & Fabaceae & & 25 & 8 & 0,2560 & 11,54 \\
Miconia ferruginata DC. & Melastomataceae & & 26 & 8 & 0,2161 & 10,99 \\
Caryocar brasiliense Cambess. & Caryocaraceae & & 24 & 7 & 0,1882 & 9,78 \\
Simarouba versicolor A. St.-Hil. & Simaroubaceae & 308 & 20 & 5 & 0,2490 & 9,43 \\
Mimosa setosissima Taub. & Fabaceae & & 32 & 5 & 0,1018 & 8,62 \\
Salacia crassifolia (Mart. ex Schult.) G. Don & Hippocrateaceae & & 20 & 8 & 0,1314 & 8,60 \\
& & & & & & continua
\end{tabular}


continuação

\begin{tabular}{|c|c|c|c|c|c|c|}
\hline Espécie & Família & $\mathrm{Nr}$ & $\mathrm{N}$ & $\mathrm{P}$ & $\mathrm{AB}$ & VI \\
\hline Byrsonima coccolobifolia Kunth & Malpighiaceae & & 18 & 9 & 0,1053 & 8,26 \\
\hline Myrsine guianensis (Aubl.) Kuntze & Myrsinaceae & & 13 & 8 & 0,0863 & 6,77 \\
\hline Byrsonima pachyphylla A. Juss. & Malpighiaceae & 302 & 15 & 7 & 0,0679 & 6,33 \\
\hline Andira vermifuga Mart. ex Benth. & Fabaceae & 325 & 15 & 6 & 0,0855 & 6,22 \\
\hline Ouratea hexasperma (A. St.-Hil.) Baill. & Ochnaceae & & 14 & 5 & 0,0944 & 5,82 \\
\hline Heteropterys byrsonimifolia A. Juss. & Malpighiaceae & 332 & 9 & 6 & 0,0770 & 5,18 \\
\hline Davilla elliptica A. St.-Hil. & Dilleniaceae & & 11 & 5 & 0,0625 & 4,81 \\
\hline Aspidosperma macrocarpon Mart. & Apocynaceae & & 10 & 5 & 0,0697 & 4,79 \\
\hline Lafoensia pacari A. St.-Hil. & Lythraceae & & 8 & 6 & 0,0488 & 4,54 \\
\hline Psidium pohlianum O. Berg & Myrtaceae & 320 & 10 & 5 & 0,0552 & 4,53 \\
\hline Vochysia thyrsoidea Pohl & Vochysiaceae & & 6 & 3 & 0,1125 & 4,12 \\
\hline Tibouchina papyrus (Pohl) Toledo & Melastomataceae & 317 & 7 & 4 & 0,0328 & 3,28 \\
\hline Connarus suberosus Planch. & Connaraceae & & 6 & 4 & 0,0295 & 3,07 \\
\hline Pouteria torta (Mart.) Radlk. & Sapotaceae & 307 & 2 & 2 & 0,1012 & 2,91 \\
\hline Kielmeyera coriacea Mart. \& Zucc. & Clusiaceae & 314 & 6 & 3 & 0,0360 & 2,77 \\
\hline Clusia weddelliana Planch. \& Triana & Clusiaceae & & 4 & 2 & 0,0664 & 2,59 \\
\hline Miconia rubiginosa (Bonpl.) DC. & Melastomataceae & 316 & 5 & 3 & 0,0315 & 2,54 \\
\hline Myrcia cordifolia O. Berg & Myrtaceae & 322 & 5 & 3 & 0,0274 & 2,47 \\
\hline Macairea radula (Bonpl.) DC. & Melastomataceae & 315 & 9 & 1 & 0,0351 & 2,37 \\
\hline Qualea multiflora Mart. & Vochysiaceae & & 3 & 3 & 0,0290 & 2,20 \\
\hline Wunderlichia mirabilis Riedel \& Baker & Asteraceae & & 4 & 2 & 0,0382 & 2,10 \\
\hline Matayba elaeagnoides Radlk. & Sapindaceae & 306 & 3 & 3 & 0,0166 & 1,98 \\
\hline Roupala montana Aubl. & Proteaceae & & 3 & 3 & 0,0119 & 1,90 \\
\hline Tabebuia ochracea (Cham.) Standl. & Bignoniaceae & & 3 & 2 & 0,0211 & 1,65 \\
\hline Kielmeyera speciosa A. St.-Hil. & Clusiaceae & & 3 & 2 & 0,0197 & 1,62 \\
\hline Styrax ferrugineus Nees \& Mart. & Styracaceae & 303 & 2 & 2 & 0,0191 & 1,46 \\
\hline Guapira noxia (Netto) Lundell & Nyctaginaceae & & 2 & 2 & 0,0172 & 1,43 \\
\hline Xylopia aromatica (Lam.) Mart. & Annonaceae & & 2 & 1 & 0,0365 & 1,36 \\
\hline Qualea grandiflora Mart. & Vochysiaceae & & 2 & 2 & 0,0104 & 1,31 \\
\hline Alchornea triplinervia (Spreng.) Müll. Arg. & Euphorbiaceae & 301 & 2 & 2 & 0,0097 & 1,30 \\
\hline Vochysia elliptica Mart. & Vochysiaceae & & 2 & 2 & 0,0097 & 1,30 \\
\hline Erythroxylum deciduum A. St.-Hil. & Erythroxylaceae & 330 & 2 & 2 & 0,0084 & 1,28 \\
\hline Eremanthus glomerulatus Less. & Asteraceae & & 2 & 2 & 0,0077 & 1,26 \\
\hline Mimosa claussenii Benth. & Fabaceae & & 2 & 2 & 0,0068 & 1,25 \\
\hline Aspidosperma tomentosum Mart. & Apocynaceae & 329 & 2 & 2 & 0,0062 & 1,24 \\
\hline Pouteria ramiflora (Mart.) Radlk. & Sapotaceae & & 2 & 1 & 0,0263 & 1,18 \\
\hline \multicolumn{7}{|l|}{ Eriotheca pubescens (Mart. \& Zucc.) } \\
\hline Schott \& Endl. & Malvaceae & & 1 & 1 & 0,0245 & 1,00 \\
\hline Vochysia rufa Mart. & Vochysiaceae & 309 & 2 & 1 & 0,0116 & 0,92 \\
\hline Vellozia squamata Pohl & Styracaceae & & 1 & 1 & 0,0183 & 0,89 \\
\hline Byrsonima verbascifolia (L.) Rich. ex A. Juss. & Malpighiaceae & & 2 & 1 & 0,0088 & 0,87 \\
\hline Erythroxylum suberosum A. St.-Hill. & Erythroxylaceae & & 2 & 1 & 0,0061 & 0,82 \\
\hline Schefflera macrocarpa (Cham. \& Schltdl.) Frodin & Araliaceae & & 1 & 1 & 0,0130 & 0,79 \\
\hline Ocotea pomaderroides (Meisn.) Mez & Verbenaceae & & 1 & 1 & 0,0095 & 0,73 \\
\hline Lauraceae sp. & Lauraceae & & 1 & 1 & 0,0089 & 0,72 \\
\hline Virola sebifera Aubl. & Myristicaceae & & 1 & 1 & 0,0060 & 0,67 \\
\hline Stryphnodendron adstringens (Mart.) Coville & Fabaceae & & 1 & 1 & 0,0054 & 0,66 \\
\hline Tibouchina sp. & Melastomataceae & & 1 & 1 & 0,0035 & 0,63 \\
\hline Erythroxylum tortuosum Mart. & Erythroxylaceae & & 1 & 1 & 0,0029 & 0,62 \\
\hline Tocoyena formosa (Cham. \& Schltdl.) K. Schum. & Rubiaceae & & 1 & 1 & 0,0033 & 0,62 \\
\hline Aegiphila lhotskiana Cham. & Lamiaceae & 328 & 1 & 1 & 0,0029 & 0,61 \\
\hline Cordiera elliptica (Cham.) Kuntze & Rubiaceae & & 1 & 1 & 0,0022 & 0,60 \\
\hline Banisteriopsis latifolia (A. Juss.) B. Gates & Malpighiaceae & 334 & 1 & 1 & 0,0020 & 0,60 \\
\hline
\end{tabular}


As famílias que mais contribuíram com a riqueza florística foram: Fabaceae, Melastomataceae e Vochysiaceae (seis espécies); Malpighiaceae (cinco); Clusiaceae, Erythroxylaceae e Myrtaceae (três) (tabela 1). Por outro lado, 25 famílias $(69,44 \%)$ foram registradas na área com apenas uma espécie e quatro famílias $(11,11 \%)$, Apocynaceae, Asteraceae, Rubiaceae e Sapotaceae com duas espécies cada.

Dezesseis famílias foram amostradas com dez ou mais indivíduos, representando conjuntamente $91,84 \%$ do total de indivíduos e $61,56 \%$ do total de espécies registrado na área. Para a maioria destas famílias a maior contribuição relativa foi em termos de número de indivíduos porém, para Malpighiaceae, Vochysiaceae, Clusiaceae e Apocynaceae a maior contribuição relativa foi em termos do número de espécies (figura 1).

As 20 espécies mais importantes em termos de VI somam $79,53 \%$ da densidade absoluta e $74,16 \%$ do VI total da comunidade. Isso indica que essas espécies ocupam importante posição na estrutura da comunidade e que as demais 45 espécies $(69,23 \%$ do total) são pouco expressivas na caracterização estrutural da vegetação

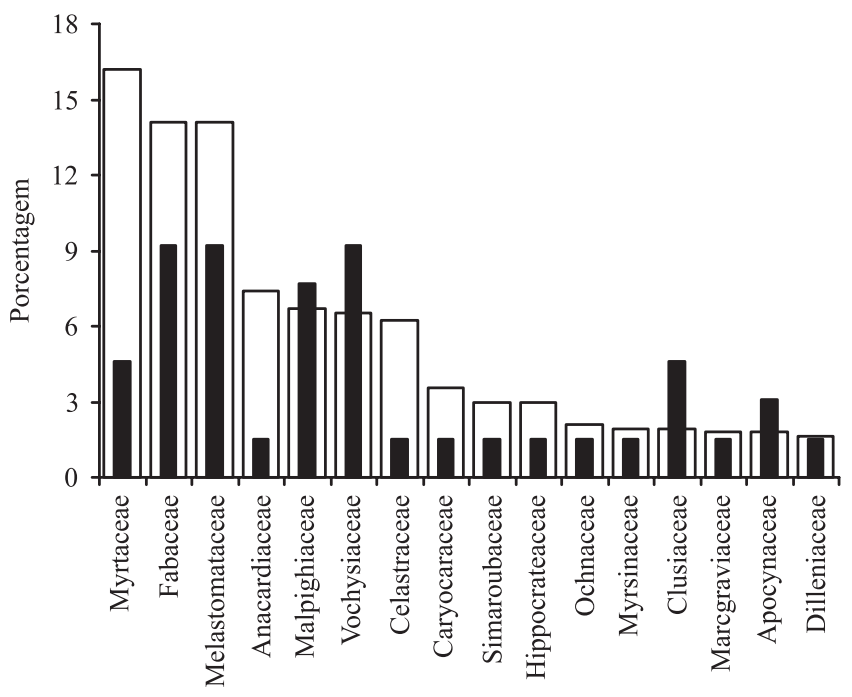

Figura 1. Porcentagem de espécies ( $\square$ ) e indivíduos $(\square)$ arbustivo-arbóreos, com DAS $\geq 5 \mathrm{~cm}$ para as principais famílias botânicas com $n \geq 10$, amostradas em 10 parcelas de $20 \times 50 \mathrm{~m}$ em um cerrado rupestre, Cocalzinho de Goiás, Goiás. As famílias estão organizadas em ordem decrescente do número de indivíduos.

Figure 1. Percentage of tree and shrub species ( $\square)$ and individuals ( $\square$ ), with DSH $\geq 5 \mathrm{~cm}$ for the main botanical families with $n \geq 10$ sampled on ten $20 \times 50$ m plots in a "cerrado rupestre", Cocalzinho de Goiás, Goiás State, Brazil. Families are ranked in decreasing order to the number of individuals. estudada (tabela 1). As espécies consideradas como raras, ou seja, aquelas espécies amostradas com no máximo um indivíduo por hectare (Martins 1991), corresponderam a $20 \%$ das espécies amostradas (13 espécies) e juntas representam 1,93\% do número de indivíduos e 3,05\% do VI total da comunidade.

As espécies mais representativas em termos estruturais apresentaram padrões distintos em relação aos parâmetros que compõem o índice de valor de importância (VI) (figura 2). Algumas espécies ocuparam posição de destaque na estrutura da comunidade principalmente em função dos seus elevados números de indivíduos, por exemplo, Psidium myrsinoides (sinonímia: Psidium myrsinites) e Mimosa setosissima. Outras espécies se destacam na ordem hierárquica do

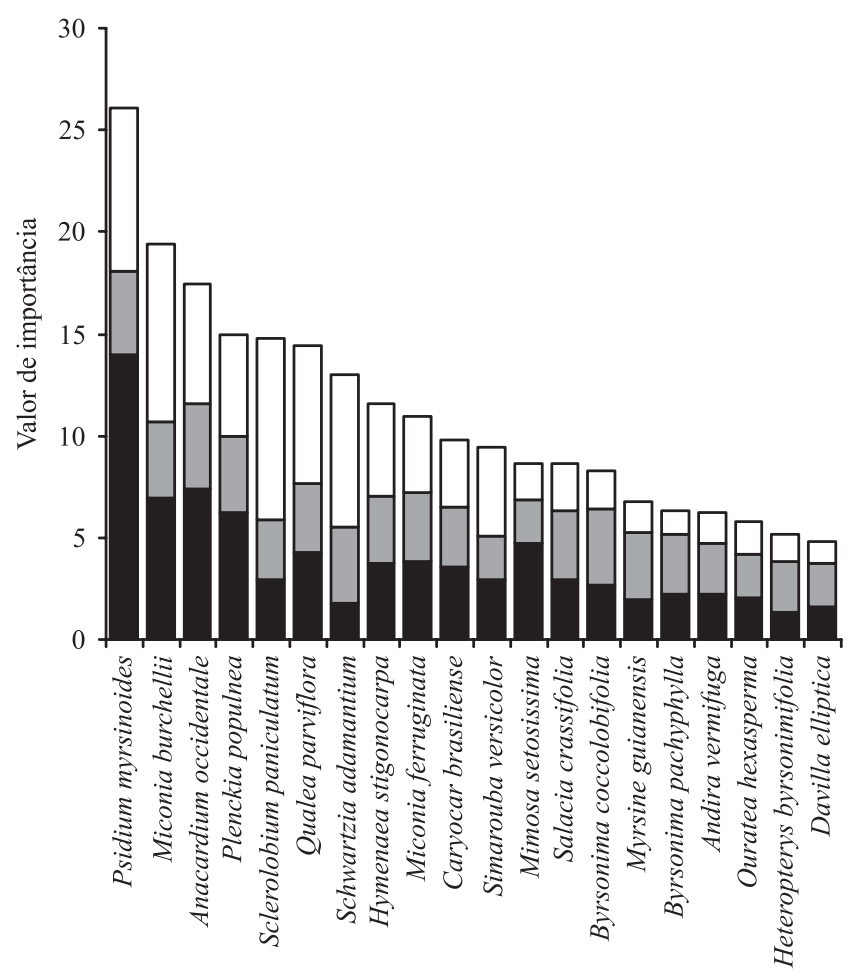

Figura 2. Distribuição do valor de importância (VI) das 20 principais espécies arbustivo-arbóreas (DAS $\geq 5 \mathrm{~cm}$ ), amostradas em 10 parcelas de $20 \times 50 \mathrm{~m}$ em um cerrado rupestre, Cocalzinho de Goiás, Goiás. O valor de importância está representado pelos três parâmetros fitossociológicos que o compõe: densidade relativa ( $\square$ ),frequiência relativa ( $\square$ ) e dominância relativa $(\square)$.

Figure 2. Distribution of the importance value (IV) of the 20 main tree and shrub species (DSH $\geq 5 \mathrm{~cm}$ ), sampled on ten $20 \times 50 \mathrm{~m}$ plots in a "cerrado rupestre", Cocalzinho de Goiás, Goiás State, Brazil. The importance value is represented by three phytosociological parameters: relative density ( $\boldsymbol{\square})$, relative frequency $(\square)$ and relative dominance $(\square)$. 
VI em função da elevada área basal individual, tal como observado para Sclerolobium paniculatum, Qualea parviflora e Schwartzia adamantium. Em alguns casos a ampla distribuição dos indivíduos nas parcelas contribui de forma expressiva para a posição das espécies na estrutura da comunidade, por exemplo, Byrsonima coccolobifolia, Heteropterys byrsonimifolia e Myrsine guianensis. Outros padrões podem emergir, tais como espécies que apresentam equilíbrio entre densidade, freqüência e dominância relativas (Hymenaea stigonocarpa, Miconia ferruginata, Caryocar brasiliense), ou dois destes três parâmetros (Miconia burchellii e Anacardium occidentale).

A distribuição de frequiência nas classes de diâmetro apresentou distribuição tendendo à exponencial negativa, ou J-invertido (figura 3), com a maioria dos indivíduos concentrados nas primeiras classes diamétricas. Em termos de altura, pode-se observar que a distribuição de frequiência tende à distribuição normal com maior número de indivíduos registrados nas quatro classes com altura entre $1,6 \mathrm{~m}$ e $3,5 \mathrm{~m}$, que juntas representam $66,17 \%$ do total de indivíduos amostrados na área (figura 4). A altura mediana foi de $2,70 \mathrm{~m}$, a altura média de $2,88 \mathrm{~m}$ (desvio padrão $\pm 1,22 \mathrm{~m}$ ) e o valor máximo de $9,50 \mathrm{~m}$, representado por um indivíduo de Sclerolobium paniculatum.

A similaridade florística, em geral, foi baixa (IS $<0,50)$ conforme sugere Kent \& Coker (1992), particularmente com as áreas de cerrado rupestre estudadas no Norte de Goiás e Sul de Tocantins (IS =
0,25 ). Por outro lado, as maiores similaridades (IS $\geq 40$ ) foram registradas com as áreas de cerrado rupestre amostradas no Parque Estadual dos Pireneus - GO e de cerrado sentido restrito sobre solos profundos estudadas em Brasília (tabela 2).

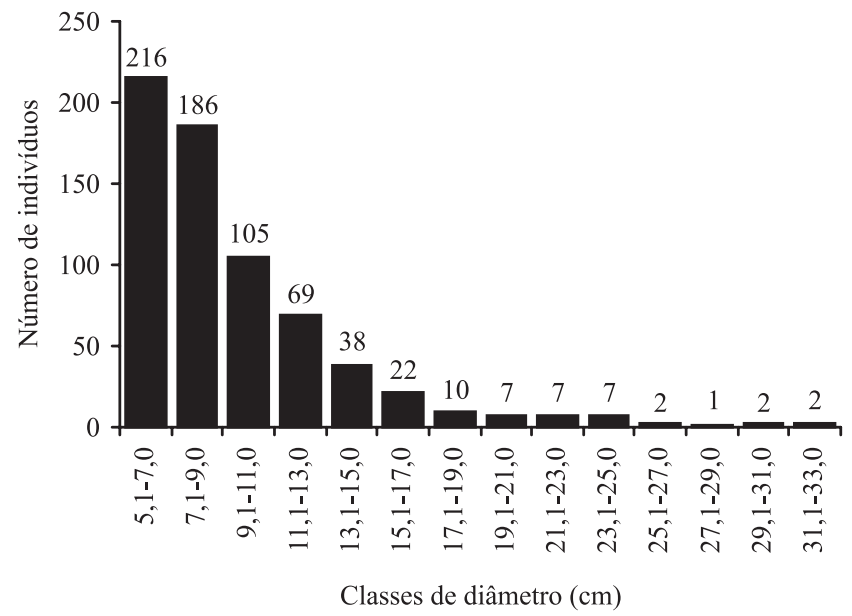

Figura 3. Distribuição de frequiência nas classes de diâmetros dos indivíduos arbustivo-arbóreos (DAS $\geq 5 \mathrm{~cm}$ ), amostrados em 10 parcelas de $20 \times 50 \mathrm{~m}$ em um cerrado rupestre, Cocalzinho de Goiás, Goiás.

Figure 3. Frequency distribution on diameter classes of trees and shrubs (DSH $\geq 5 \mathrm{~cm}$ ), sampled on ten $20 \times 50 \mathrm{~m}$ plots in a “cerrado rupestre", Cocalzinho de Goiás, Goiás State, Brazil.

Tabela 2. Comparação florística e estrutural entre estudos realizados com espécies arbustivo-arbóreas (DAS $\geq 5 \mathrm{~cm}$ ), excluídos os indivíduos mortos, em cerrado rupestre ( 1 a 5) e cerrado sentido restrito sobre solos profundos (6 a 9) do Brasil Central. $\left(\mathrm{DA}=\right.$ densidade absoluta (indivíduos ha $\left.{ }^{-1}\right), \mathrm{AB}=$ área basal $\left(\mathrm{m}^{2} \mathrm{ha}^{-1}\right), \mathrm{S}=$ número de espécies, $\mathrm{H}^{\prime}=$ índice de diversidade de Shannon, IS = índice de similaridade de Sørensen, P.E. = Parque Estadual e P.N. = Parque Nacional). Em cada estudo foram amostradas 10 parcelas de $20 \times 50 \mathrm{~m}$.

Table 2. Structural and floristic comparisons between studies performed with woody species (DAS $\geq 5 \mathrm{~cm}$ ), excluding dead trees, in "cerrado rupestre" (1 to 5) and cerrado stricto sensu on deep soils (6 to 9), central Brazil. (DA = density (individuals $\left.\mathrm{ha}^{-1}\right), \mathrm{AB}=$ basal area $\left(\mathrm{m}^{2} \mathrm{ha}^{-1}\right), \mathrm{S}=$ species number, $\mathrm{H}^{\prime}=$ Shannon index, IS = Sørensen index, P.E. $=$ State Park and P.N. = National Park). Was sampled ten $20 \times 50 \mathrm{~m}$ plots in each studies.

\begin{tabular}{lcccccl}
\hline Áreas & DA & AB & S & H' & IS & Referência \\
\hline 1. Fazenda Cabana dos Pireneus, GO & 674 & 5,67 & 65 & 3,45 & - & Presente estudo \\
2. P.E. dos Pireneus, GO & 972 & 10,02 & 65 & 3,65 & 0,40 & Moura 2006 \\
3. P.E. dos Pireneus, GO & 461 & 3,63 & 56 & 3,33 & 0,42 & Moura 2006 \\
4. Fazenda Sucupira, DF & 607 & 3,59 & 51 & 3,09 & 0,33 & Amaral et al. 2006 \\
5. Norte de Goiás e Sul de Tocantins & 797 & 8,09 & 87 & 2,87 & 0,25 & Felfili \& Fagg 2007 \\
6. Jardim Botânico de Brasília, DFIII & 1.174 & 8,18 & 53 & 3,16 & 0,40 & Fonseca \& Silva Júnior 2004 \\
7. P.N. Chapada dos Veadeiros, GO & 1.016 & 8,92 & 80 & 3,57 & 0,38 & Felfili et al. 2007 \\
8. P.N. de Brasília, DF & 894 & 7,45 & 55 & 3,42 & 0,38 & Felfili et al. 1994 \\
9. Fazenda Água Limpa, DF & 948 & 7,22 & 61 & 3,46 & 0,43 & Silva 1999, Felfili et al. 2000
\end{tabular}

${ }^{\text {I }}$ Portal, ${ }^{\text {II }}$ Três Picos e ${ }^{\text {III Interflúvio. }}$ 


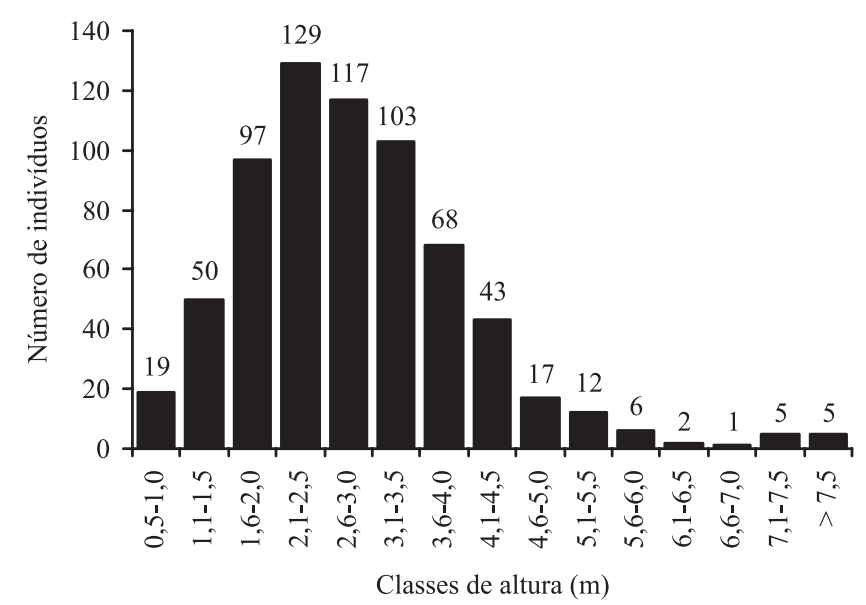

Figura 4. Distribuição de freqüência nas classes de altura dos indivíduos arbustivo-arbóreos (DAS $\geq 5 \mathrm{~cm}$ ), amostrados em 10 parcelas de $20 \times 50 \mathrm{~m}$ em um cerrado rupestre, Cocalzinho de Goiás, Goiás.

Figure 4. Frequency distribution on height classes of trees and shrubs (DSH $\geq 5 \mathrm{~cm}$ ), sampled on ten $20 \times 50 \mathrm{~m}$ plots in a cerrado rupestre, Cocalzinho de Goiás, Goiás State, Brazil.

\section{Discussão}

A riqueza de espécies (65 espécies) e os índices de diversidade de Shannon $\left(\mathrm{H}^{\prime}=3,45\right.$ nats indivíduo $\left.{ }^{-1}\right)$ e de eqüabilidade de Pielou $\left(\mathrm{J}^{\prime}=0,827\right)$ registrados para a comunidade arbustivo-arbórea estudada (DAS $\geq 5 \mathrm{~cm}$ ) estão dentro dos intervalos estabelecidos na maioria dos levantamentos realizados em áreas de cerrado sentido restrito sobre solos profundos (Felfili 2002, Felfili et al. 1994, 2001, 2007, Nunes et al. 2002, Fonseca \& Silva Junior 2004) e áreas de cerrado rupestre (Amaral et al. 2006, Moura 2006, Felfili \& Fagg 2007) (tabela 2).

A composição de espécies do cerrado rupestre estudado foi representada por componentes da flora lenhosa encontrados em outras subdivisões fitofisionômicas do cerrado sentido restrito, principalmente, espécies das famílias Clusiaceae, Erythroxylaceae, Fabaceae, Malpighiaceae, Melastomataceae, Myrtaceae, Rubiaceae e Vochysiaceae (Mendonça et al. 1998, Ratter et al. 2003). Também foram registrados elementos citados como de campo rupestre, representados pelas famílias Asteraceae, Celastraceae, Velloziaceae e Verbenaceae (Eiten 1994).

De acordo com Eiten (1994), a vegetação do cerrado sentido restrito também pode ser encontrada em ambientes tipicamente de campo rupestre. Certamente o autor se referiu às manchas de cerrado rupestre que, segundo ele, foram encontradas no Estado de Goiás, próximo aos Municípios de Cristalina, Caldas Novas, Goiás Velho e na Serra dos Pireneus. Tal fato pode, de certo modo, justificar o registro de algumas espécies de campo rupestre que ocorreram também em áreas de cerrado sobre afloramentos rochosos, como foi o caso do cerrado rupestre estudado.

Semelhante ao que ocorre com a composição florística do cerradão, que possui uma flora formada por uma mistura de elementos das formações savânicas e florestais do bioma (Ribeiro \& Walter 1998, Felfili 2002), o cerrado rupestre também parece não possuir uma flora lenhosa própria. A sua composição florística é caracterizada por espécies arbustivo-arbóreas das demais formações savânicas, principalmente do cerrado sentido restrito sobre solos profundos (por exemplo, Byrsonima coccolobifolia e B. pachyphylla; Caryocar brasiliense; Connarus suberosus; Erythroxylum deciduum; E. suberosum e E. tortuosum; Hymenaea stigonocarpa; Kielmeyera coriacea e K. speciosa; Myrsine guianensis; Ouratea hexasperma; Pouteria ramiflora e P. torta; Qualea parviflora e $Q$. grandiflora; Roupala montana e Stryphnodendron adstringens). Tal como no cerradão, ocorrem com menor representatividade as espécies típicas de formações florestais do bioma (por exemplo, Alchornea triplinervia, Matayba elaeagnoides, Simarouba versicolor e Virola sebifera) e as peculiares de ambientes rupestres (por exemplo, Clusia weddelliana, Schwartzia adamantium, Mimosa setosissima, Tibouchina papyrus e Wunderlichia mirabilis).

Os baixos valores registrados pelo índice de Sørensen (IS < 0,50), corroboram os estudos que indicam a grande heterogeneidade florística encontrada em áreas de cerrado sentido restrito (Felfili et al. 1994, OliveiraFilho \& Ratter 2002, Ratter et al. 2000, 2003), geralmente distribuído em mosaicos (Felfili 2002, Felfili et al. 2001). Provavelmente a proximidade geográfica e, consequientemente, a semelhança nas condições ambientais locais influenciou na maior similaridade entre a área do presente estudo e as áreas de cerrado rupestre amostradas no Parque Estadual dos Pireneus, GO (Moura 2006). A semelhança florística com as áreas de cerrado sobre solos profundos amostrado na Fazenda Água Limpa (Silva 1999, Felfili et al. 2000) e no Jardim Botânico de Brasília (Fonseca \& Silva Júnior 2004) reforça a idéia de que a composição florística do cerrado rupestre é influenciada pela flora do cerrado sentido restrito sobre solos profundos. Por outro lado, a ampla área de amostragem adotada por Felfili \& Fagg (2007), incluindo distintos tipos de substratos resultou em elevada riqueza de espécies e refletiu como a menor semelhança florística entre a área do presente estudo e as demais áreas comparadas. 
Pelo menos quatorze das vinte espécies registradas com maiores valores de importância no presente estudo são comumente encontradas em áreas de cerrado sentido restrito sobre solos profundos (Mendonça et al. 1998, Ratter et al. 2000, Nunes et al. 2002). Dentre elas, Caryocar brasiliense, Qualea parviflora, Hymenaea stigonocarpa, Byrsonima coccolobifolia e B. pachyphylla apresentam ampla distribuição na região de domínio do Cerrado (Ratter et al. 2000, 2003). Nunes et al. (2002) citam Ouratea hexasperma como uma das espécies mais abundante e muito freqüente em áreas de cerrado sentido restrito sobre Latossolo, no Distrito Federal. Por outro lado, Plenckia populnea é citada por Ratter et al. (2000) como de distribuição restrita a algumas áreas de cerrado sentido restrito e Schwartzia adamantium como espécie peculiar de ambientes rupestres.

As propriedades edáficas restritas e as condições climáticas particulares em ambientes rupestres são citadas como favoráveis à ocorrência de um grande número de espécies endêmicas e raras (Pirani et al. 1994, Harley 1995, Romero \& Nakajima 1999, Simon \& Proença 2000). No entanto, das 65 espécies registradas na área, apenas Clusia weddelliana, Schwartzia adamantium, Mimosa setosissima, Tibouchina papyrus e Wunderlichia mirabilis podem ser citadas como peculiares de ambientes rupestres (Ribeiro \& Walter 1998, Ratter et al. 2000). O elevado endemismo citado para ambientes rupestres parece estar mais fortemente associado ao estrato herbáceo-subarbustivo, representado pelas famílias Asteraceae, Celastraceae, Cyperaceae, Eriocaulaceae, Lamiaceae, Melastomataceae, Poaceae, Velloziaceae, Verbenaceae e Xyridaceae (Eiten 1994, Pirani et al. 1994, Harley 1995, Ribeiro \& Walter 1998, Romero \& Martins 2002), estrato não amostrado no presente estudo.

Os valores de área basal e densidade registrados no presente estudo, 674 indivíduos ha-1 e 5,6720 $\mathrm{m}^{2}$ ha $^{-1}$, respectivamente, ocuparam posição intermediária entre as áreas de cerrado rupestre e cerrado sentido restrito sobre solos profundos analisadas. Nunes et al. (2002) estudaram dez sítios, num total de 100 parcelas de $20 \times$ $50 \mathrm{~m}$, amostradas em áreas de cerrado sentido restrito bem preservado sobre Latossolo, no Distrito Federal, adotando o mesmo critério de inclusão usado no presente estudo (DAS $\geq 5 \mathrm{~cm}$ ), encontraram densidade média de 1.042,8 $( \pm 35,0)$ indivíduos $\mathrm{ha}^{-1}$, enquanto a mediana da área basal foi de 7,48 $\mathrm{m}^{2} \mathrm{ha}^{-1}$. Provavelmente, as menores densidade e área basal registradas no cerrado rupestre estudado podem ser reflexo das condições ambientais limitantes, principalmente edáficas. Além da pouca profundidade do solo, o pouco solo disponível é pobre em função da rocha de origem, em geral quartzito e arenito, apresenta baixo $\mathrm{pH}$ e alta concentração de alumínio trocável (Harley 1995, Reatto et al. 1998, Benites et al. 2003), condições que podem ter reduzido a densidade e porte dos indivíduos arbustivo-arbóreos na área estudada.

Normalmente os indivíduos arbustivo-arbóreos que ocorrem no cerrado rupestre se concentram em microsítios existentes nas reentrâncias e nos degraus formados entre as rochas, onde as condições para o estabelecimento são favoráveis. Segundo Ribeiro \& Walter (1998), isto explica a ocorrência de agrupamentos de indivíduos arbustivo-arbóreos em locais pontuais, cuja presença certamente é condicionada pelas propriedades edáficas, principalmente disponibilidade, profundidade e umidade do solo. Isto faz com que o cerrado rupestre analisado se assemelhe estruturalmente mais ao cerrado ralo do que as demais subdivisões fisionômicas do cerrado sentido restrito (Ribeiro \& Walter 1998). Tanto o cerrado rupestre como o cerrado ralo, apresentam cobertura arbórea que varia de 5\% a $20 \%$ e altura média de 2 a 4 m e 2 a $3 \mathrm{~m}$, respectivamente (Ribeiro \& Walter 1998). No entanto, para esses autores, o cerrado rupestre se diferencia do cerrado ralo, como das demais fitofisionomias savânicas, em função das condições ambientais em que ele ocorre.

Durante a realização dos trabalhos de campo, foi registrada a ocorrência de queimada na área, atingindo oito das dez parcelas inventariadas. Além disso, mesmo antes da passagem deste fogo na área, muitos indivíduos inventariados apresentaram sinais de queimada, indicando que o fogo é um fator ambiental freqüente na região. Queimadas frequientes modificam a estrutura da vegetação arbustivo-arbórea, refletindo em redução de biomassa, através do aumento na taxa de mortalidade dos indivíduos lenhosos e da redução na taxa de recrutamento (Moreira 2000, Hoffmann \& Moreira 2002, Miranda et al. 2004). Assim, os menores valores de densidade e área basal encontrados na vegetação arbustivo-arbórea estudada podem também estar associados à ocorrência de queimadas, mesmo que em menor intensidade, devido à reduzida disponibilidade de material combustível do estrato herbáceo. No entanto, as limitações edáficas e as queimadas não alteraram os padrões de distribuição diamétrica e de altura, uma vez que os padrões encontrados neste estudo foram semelhantes àqueles de outras áreas de cerrado sentido restrito sobre solos profundos (Felfili et al. 1994, 2001) e sobre afloramentos rochosos (Amaral et al. 2006, Felfili \& Fagg 2007).

Conforme discutido acima, a flora arbustivo-arbórea do cerrado rupestre estudado apresentou composição florística, riqueza e diversidade de espécies semelhantes àquelas encontradas nas outras subdivisões fitofisionômicas 
do cerrado sentido restrito (cerrado denso, cerrado típico e cerrado ralo), com menor representatividade de espécies das formações florestais do bioma e de espécies endêmicas de ambientes rupestres. Por outro lado, a densidade e área basal se assemelham aos valores registrados em áreas de cerrado ralo. Todavia, novos levantamentos fitossociológicos devem ser realizados em outras áreas de cerrado rupestre para verificar se esta tendência se confirma.

Agradecimentos - Ao Prof. Renato Gomes Faria (Universidade Federal de Sergipe), por incentivar a realização deste trabalho, acompanhar os trabalhos de campo e gentilmente ceder abrigo em sua "casa de campo" (Cocalzinho de Goiás, GO). Ao Biólogo Welington Zahn Silva pela ajuda no levantamento da vegetação. A Profa. Carolyn Proença (Universidade de Brasília, Departamento de Botânica) e ao Prof. Manoel Cláudio da Silva Júnior (Universidade de Brasília, Departamento de Engenharia Florestal) pela inestimável ajuda na identificação do material botânico.

\section{Referências bibliográficas}

AMARAL, A.G., PEREIRA, F.F.O. \& MUNHOZ, C.B.R. 2006. Fitossociologia de uma área de cerrado rupestre na Fazenda Sucupira, Brasília-DF. Revista Cerne 12: 350-359.

APG II. 2003. An update of the angiosperm phylogeny group classification for the orders and families of flowering plants: APG II. The Linnean Society of London. Botanical Journal of the Linnean Society 141:399-436.

BENITES, V.M., CAIAFA, A.N., MENDONÇA, E. DE SÁ, SCHAEFER, C.E. \& KER, J.C. 2003. Solos e vegetação nos complexos rupestres de altitude da Mantiqueira e do Espinhaço. Floresta e Ambiente 10:76-85.

EITEN, G. 1994. Vegetação. In Cerrado: caracterização, ocupação e perspectivas, $2^{\mathrm{a}}$ ed. (M.N. Pinto, org.). Editora Universidade de Brasília, Brasília, p.17-74.

FELFILI, J.M. 2002. Padrões de diversidade do Cerrado do Centro-Oeste brasileiro. In Biodiversidade, conservação e uso sustentável da flora do Brasil (E.L. Araújo, A.N. Moura, E.S.B. Sampaio, L.M.S. Gestinari \& J.M.T. Carneiro, eds.). Universidade Federal Rural de Pernambuco, Recife, p.58-61.

FELFILI, J.M. \& FAGG, C.W. 2007. Floristic composition, diversity and structure of the "cerrado" sensu stricto on rocky soils in northern Goiás and southern Tocantins, Brazil. Revista Brasileira de Botânica 30: 375-385.

FELFILI, J.M., FILGUEIRAS, T.S., HARIDASSAN, M., SILVA JÚNIOR, M.C., MENDONÇA, R.C. \& REZENDE, A.V. 1994. Projeto biogeografia do bioma cerrado: vegetação e solos. Cadernos de Geociências 12:75-166.
FELFILI, J.M., REZENDE, A.V., SILVA JÚNIOR, M.C. \& SILVA, M.A. 2000. Change in the floristic composition of cerrado sensu stricto in Brazil over a nine-year period. Journal of Tropical Ecology 16:579-590.

FELFILI, J.M., SEVILHA, A.C. \& SILVA JÚNIOR, M.C. 2001. Comparação entre as unidades fitogeográficas Chapada Pratinha, Veadeiros e Espigão Mestre do São Francisco. In Biogeografia do Bioma Cerrado: estudo fitofisionômico na Chapada do Espigão Mestre do São Francisco (J.M. Felfili \& M.C. Silva Júnior, orgs.). Departamento de Engenharia Florestal da Universidade de Brasília, Brasília, p.80-102.

FELFILI, J.M., REZENDE, A.V., SILVA JÚNIOR, M.C., SILVA, P.E.N, WALTER, B.M.T., ENCINAS, J.I. \& SILVA, M.A. 2007. Fitossociologia da vegetação arbórea. In Biogeografia do bioma Cerrado: vegetação e solos da Chapada dos Veadeiros (J.M. Felfili, A.V. Rezende \& M.C. Silva Júnior, orgs.). Editora Universidade de Brasília, Brasília, p.45-96.

FONSECA, M.S. \& SILVA JÚNIOR, M.C. 2004. Fitossociologia e similaridade florística entre trechos de Cerrado sentido restrito em interflúvio e em vale no Jardim Botânico de Brasília, DF. Acta Botanica Brasilica 18:19-29.

HARLEY, R.M. 1995. Introduction. In Flora of the Pico das Almas - Chapada Diamantina, Bahia, Brazil (B.L. Stannard, ed.). Royal Botanical Gardens, Kew, p.1-78.

HOFFMANN, W.A. \& MOREIRA, A.G. 2002. The role of fire in population dynamics of woody plants. In The Cerrados of Brazil (P.S. Oliveira \& R.J. Marquis, eds.). Columbia University Press, New York, p.159-177.

KENT, M. \& COKER, P. 1992. Vegetation description and analysis. Belhaven Press, London.

MARTINS, F.R. 1991. Estrutura de uma floresta mesófila. Editora da Unicamp, Campinas.

MARTINS, F.R. 2004. O papel da fitossociologia na conservação e na bioprospecção. In Anais do 55을 Congresso Nacional de Botânica, Viçosa. Simpósio, Palestras e Mesas Redondas (CD-Rom).

MEIRA NETO, J.A.A. \& SAPORETTI JÚNIOR, A.W. 2002. Parâmetros fitossociológicos de um cerrado no Parque Nacional da Serra do Cipó, MG. Revista Árvore 26:645-648.

MENDONÇA, R.C., FELFILI, J.M., WALTER, B.M. T., SILVA JÚNIOR, M.C., REZENDE, A.V., FILGUEIRAS, T.S. \& NOGUEIRA, P.E. 1998. Flora vascular do Cerrado. In Cerrado: ambiente e flora (S.M. Sano \& S.P. Almeida, eds.). Embrapa/CPAC, Planaltina, p.289-556.

MIRANDA, H.S., SATO, M.N., ANDRADE, S.M.A., HARIDASAN, M. \& MORAIS, H.C. 2004. Queimadas de Cerrado: caracterização e impactos. In Cerrado: ecologia e caracterização (L.M.S. Aguiar \& A.J.A. Camargo, eds.). Embrapa/CPAC, Planaltina, p.69-123. 
MOREIRA, A.G. 2000. Effects of fire protection on savanna structure in Central Brazil. Journal of Biogeography 2:1021-1029.

MOURA, I. 2006. Fitossociologia de cerrado sensu stricto em afloramentos rochosos no Parque Estadual dos Pireneus, Pirenópolis, Goiás. Dissertação de mestrado em Botânica, Universidade Federal de Goiás, Goiânia.

MUELLER-DOMBOIS, D. \& ELLENBERG, H. 1974. Aims and methods of vegetation ecology. John Wiley and Sons, New York.

NIMER, E. 1989. Climatologia do Brasil. IBGE, Rio de Janeiro.

NUNES, R.V., SILVA JÚNIOR, M.C.S., FELFILI, J.M. \& WALTER, B.M.T. 2002. Intervalos de classe para abundância, dominância e freqüência do componente lenhoso do cerrado sentido restrito no Distrito Federal. Revista Árvore 26:173-182.

OLIVEIRA-FILHO, A.T. 1994. Estudos ecológicos da vegetação como subsídios para programas de revegetação com espécies nativas: uma proposta metodológica. Cerne 1:64-72.

OLIVEIRA-FILHO, A.T. \& FLUMINHAN-FILHO, M. 1999. Ecologia da vegetação do Parque Florestal Quedas do Rio Bonito. Cerne 5:51-64.

OLIVEIRA-FILHO, A.T. \& RATTER, J.A. 2002. Vegetation physionomies and woody flora of the cerrado biome. In The cerrados of Brazil (P.S. Oliveira \& R.J. Marquis, eds.). Columbia University Press, New York, p.91-120.

PIRANI, J.R., GIULIETTI, A.M. \& MELLO-SILVA, R. 1994. Checklist and patterns of geographic distribution of the vegetation of Serra do Ambrósio, Minas Gerais, Brazil. Revista Brasileira de Botânica 17:133-147.

RATTER, J.A., BRIDGEWATER, S., RIBEIRO, J.F., DIAS, T.A.B. \& SILVA, M.R. 2000. Estudo preliminar da distribuição das espécies lenhosas da fitofisionomia cerrado sentido restrito nos estados compreendidos pelo bioma Cerrado. Boletim Herbário Ezechias Paulo Heringer 5:5-43.
RATTER, J.A., BRIDGEWATER, S. \& RIBEIRO, J.F. 2003. Analysis of the floristic composition of the Brazilian cerrado vegetation III: comparison of the woody vegetation of 376 areas. Edinburgh Journal of Botany 60:57-109.

REATTO, A., CORREIA, J.R. \& SPERA, S.T. 1998. Solos do Bioma do Cerrado: aspectos pedológicos. In Cerrado: ambiente e flora (S.M. Sano \& S.P. Almeida, eds.). Embrapa/CPAC, Planaltina, p.47-86.

RIBEIRO, J.F. \& WALTER, B.M.T. 1998. Fitofisionomias do Bioma Cerrado. In Cerrado: ambiente e flora (S.M. Sano \& S.P. Almeida, eds.). Embrapa/CPAC, Planaltina, p.89-166.

ROMERO, R. \& MARTINS, A.B. 2002. Melastomataceae do Parque Nacional da Serra da Canastra, Minas Gerais, Brasil. Revista Brasileira de Botânica 25:19-24.

ROMERO, R \& NAKAJIMA, J.N. 1999. Espécies endêmicas do Parque Nacional da Serra da Canastra. Revista Brasileira de Botânica 22:259-265.

SCOLFORO, J.R.S. 1993. Inventário florestal. Escola Superior de Agricultura de Lavras/FAEPE, Lavras.

SHEPHERD, G.J. 1994. Fitopac: manual do usuário. Departamento de Botânica da Unicamp, Campinas.

SILVA, M.A. 1999. Mudança na composição florística e estrutura de um cerrado sensu stricto, em um período de 12 anos (1985-1997), na Fazenda Água Limpa (FAL) - Distrito Federal. Dissertação de mestrado em Ciências Florestais, Universidade de Brasília, Brasília.

SIMON, M.F. \& PROENÇA, C. 2000. Phytogeographic patterns of Mimosa (Mimosoideae, Leguminosae) in the Cerrado biome of Brazil: an indicator genus of highaltitude center of endemism? Biological Conservation 96:279-296.

WALTER, B.H. 2006. Fitofisionomias do bioma Cerrado: síntese terminológica e relações florísticas. Tese de doutorado em Ecologia, Universidade de Brasília, Brasília.

WARMING, E. 1973. Lagoa Santa. (tradução de A. Loefgren). Editora Itatiaia/EDUSP, Belo Horizonte/São Paulo. 